\title{
Leyes de presupuestos mínimos de protección ambiental. Sobre glaciares, humedales y la emergencia del carácter político de categorías despolitizadas
}

\author{
Patricio H Straccia ${ }^{1,2} \bowtie$ \& María L. Isla RafFaele ${ }^{12,3}$ \\ ${ }^{1}$ Cátedra de Extensión y Sociología Rurales, Facultad de Agronomía, UBA. ${ }^{2}$ Consejo Nacional de Investigaciones Científicas y \\ Técnicas (CONICET). ${ }^{3}$ Instituto de Geografía Romualdo Ardissone, Facultad de Filosofía y Letras, UBA.
}

\begin{abstract}
Resumen. En este artículo analizamos los modos en que ciertas categorías son re-politizadas en los procesos de producción de leyes de presupuestos mínimos en la Argentina. Para ello, focalizamos nuestro estudio en dos normativas ambientales de esta índole: la "Ley de Glaciares" y la "Ley de Humedales". Retomamos las perspectivas que señalan que todo proceso de conservación no es únicamente ecológico, sino también político, y a través de un análisis documental complementado con entrevistas etnográficas e instancias de observación participante ponemos de manifiesto cómo emerge el carácter político de distintas categorías vinculadas al dominio de 'lo natural', como 'glaciar', 'ambiente periglacial' o 'humedal', en los procesos de producción de normativas ambientales. Si la condición post-política tiene como fin vaciar la arena política de todo desacuerdo o crítica radical, coincidimos con quienes sostienen que la reemergencia del carácter político de este tipo de categorías evidencia la omnipresencia de las relaciones de fuerza entre los múltiples agentes que participan en dichas arenas (incluyendo a los científicos) y su inmanencia en un campo político. Y sostenemos que constituye un primer paso necesario para pensar alternativas que puedan modificar las relaciones sociales que, en última instancia, hacen posible los regímenes actuales de apropiación de la naturaleza.
\end{abstract}

[Palabras clave: Ley de Glaciares, Ley de Humedales, leyes de presupuestos mínimos, politización de la naturaleza]

\begin{abstract}
Aвstract. Laws on minimum standards for environmental protection. Glaciers, wetlands and the emergence of the political character of de-politicized categories. In this article we analyze the ways in which certain categories are re-politicized in the processes of formulation of laws on minimum standards for environmental protection in Argentina. To do so, we focus our study on two specific environmental regulations: the "Glaciers $\mathrm{Law}^{\prime}$ and the "Wetlands Law". We resume the perspectives that highlight the fact that any conservation process is not only ecological, but also political, and through a documentary analysis supplemented with ethnographic interviews and instances of participant observation we show how the political nature of diverse categories linked to the domain of 'the natural', such as 'glacier', 'periglacial environment' or 'wetland', emerge in the processes of formulation of environmental regulations. If the post-political condition aims to empty the political arena of any disagreement or radical critique, we agree with those who maintain that the reemergence of the political character of this type of category demonstrates the omnipresence of power relations and their immanence in a political field. And we argue that it constitutes a necessary first step in order to think about alternatives that could modify the social relations that make possible the current regimes of appropriation of nature.
\end{abstract}

[Keywords: Glacier Law, Wetlands Law, politicization of nature, Law on Minimum Standards for Conservation]

\section{INTRODUCCIÓN}

En este artículo analizaremos los modos en que ciertas categorías vinculadas al dominio de lo ambiental (como 'glaciar', 'ambiente periglacial' y 'humedal') son re-politizadas en los procesos de producción de leyes de presupuestos mínimos en Argentina. Para ello, enfocaremos nuestro estudio en dos leyes cuyos debates se hicieron presentes en la escena pública y en la arena legislativa en la última década: la "Ley de Glaciares" (Ley Nacional 26639 de Presupuestos Mínimos para la Preservación de los Glaciares y el Ambiente Periglacial) y la "Ley de Humedales" (Proyecto

Editor asociado: Matías Mastrangelo de Ley de Presupuestos Mínimos para la Conservación, Protección, Restauración Ecológica y Uso Racional y Sostenible de los Humedales). Se trata de dos políticas públicas (Jaime et al. 2013) que tienen como objetivo regular las formas de uso y apropiación de la naturaleza a través de la aplicación de diferentes instrumentos de política ambiental.

En los últimos años, el cuerpo de estudios que ha tenido a las políticas públicas como objeto de análisis se ha incrementado (Shore 2010). Estas políticas se construyen a lo largo de un proceso que se desarrolla en 
múltiples instancias sociopolíticas en las que convergen diversos agentes que tienen intereses específicos. En el caso de las políticas ambientales, los (des)acuerdos resultantes condensan e instituyen concepciones particulares acerca de las relaciones que las sociedades humanas deberían establecer con la naturaleza (Beltrán et al. 2008). La ecología política, en tanto campo de estudio que discute las relaciones de poder en torno a la naturaleza (en términos de su fabricación social, apropiación y uso), ha mostrado cómo estas políticas se constituyen en campos de fuerzas atravesado por relaciones de poder y donde lo caracterizado como 'natural' es también político (Straccia and Pizarro 2019).

En la Argentina, la cuestión ambiental se institucionalizó a través de la sanción de leyes de presupuestos mínimos de protección ambiental. Si bien el art. 124 de la Constitución Nacional (1994) establece que corresponde a las provincias el dominio originario de sus recursos naturales, el art. 41 delega sobre la Nación la atribución de dictar las normas que contengan los presupuestos mínimos de protección y encarga a las provincias la sanción de las normas necesarias para complementarlas. De este modo, se concedería una tutela ambiental uniforme para todo el territorio nacional y se aseguraría su protección. Así, el ambiente ha sido progresivamente incorporado como objeto de legislación a nivel nacional y provincial (Esain 2004): la Ley General del Ambiente (LN 25675) fue una de las primeras leyes de presupuestos mínimos sancionada en nuestro país, en 2002, y desde entonces se elaboraron diversas normas que prescriben las formas de uso y apropiación del ambiente en diferentes tipos de ecosistemas.

En relación con las temáticas ambientales, existen diversos ejemplos en los que el carácter político del conocimiento científico se hace evidente. En este sentido, la investigación antropológica de Blois (2017) sobre el debate en torno a los agroquímicos en Argentina resulta paradigmática, y ciertas elecciones conceptuales en las producciones técnicocientíficas reflejan esta cuestión (¿productos fitosanitarios, agroquímicos o agrotóxicos?). Lo propio se observa en aquellos estudios socioculturales desarrollados en Latinoamérica que cuestionan la noción de 'bioprospección' e indican que 'biopiratería' sería una conceptualización más apropiada para esos procesos (Martínez Alier 2012).
Sin embargo, diversos autores postulan que, complementariamente, se produjeron procesos de despolitización de otras categorías vinculadas al dominio de lo ambiental. Según Swyngedouw (2011), la condición post-política de aquello que denominamos genéricamente 'Naturaleza' es el resultado de procesos de despolitización que la ubican "más allá de lo político, es decir, más allá del espacio de la disputa pública, de la contestación y el desacuerdo" (op. cit.: 43). Para Morton (2007), esto permite obviar su carácter escurridizo e ignorar sus multiplicidades, inconsistencias, e incoherencias, pese a que existen múltiples definiciones sobre qué sería la naturaleza (Castro 2011). Algo similar puede señalarse en lo referido a la categoría 'servicios ecosistémicos', como lo reseñamos en Straccia y Pizarro (2017). En todos los casos, se trata de categorías que se constituyen dentro del universo de sentido que construye al mundo social como un ente separado del mundo natural, y que al mismo tiempo define que los científicos son quienes deben producir conocimiento en relación con ellas. El discurso técnico-científico, así, se ve legitimado por su efecto de verdad y de objetividad.

Si retomamos algunos elementos de la teoría de Laclau, podemos afirmar que conceptos como 'Naturaleza' o 'Sustentabilidad' se han convertido en significantes tendencialmente vacíos, esto es, significantes pretendidamente universales y totalizantes que se particularizan de formas específicas y articulan sentidos diferentes (Balsa 2011; Swyngedouw 2011). Pese a que estos procesos de despolitización pretenden restringir los espacios de disputa pública, la experiencia de la Argentina nos permite afirmar que la producción de leyes de presupuestos mínimos es eminentemente conflictiva, dado que se evidencia una tensión entre distintas lógicas de apropiación y uso social de la naturaleza (Ferrero and De Micco 2011). En esta línea, en la última década proliferaron estudios que analizan los conflictos existentes en torno a este tipo de leyes, tanto en los procesos de formulación de las normas nacionales (Isla Raffaele 2015; Langbehn 2016; Monkes 2017) como en los procesos de elaboración e implementación de las normas provinciales complementarias (entre otros, Gutiérrez 2017; Aguiar et al. 2018; Straccia 2019). En estos procesos, el carácter político de las categorías ambientales emerge con mayor intensidad (Brosius 1999).

A partir de estos elementos teóricoconceptuales, el objetivo de este artículo 
es analizar dos leyes de presupuestos mínimos, la "Ley de Glaciares" (sancionada definitivamente en 2010) y la "Ley de Humedales" (que pese a obtener media sanción en la Cámara de Senadores en dos ocasiones diferentes nunca logró ser sancionada en la Cámara de Diputados), haciendo foco en las formas en que ciertas categorías son re-politizadas en los procesos de formulación, sanción e implementación de ambas políticas. Para ello, luego de presentar las herramientas metodológicas utilizadas en nuestro trabajo, caracterizaremos a la "Ley de Glaciares" y haremos explícitos los mecanismos a través de los cuales emerge el carácter político de conceptos como 'glaciares' y 'ambiente periglacial'. A continuación, caracterizaremos a la "Ley de Humedales" y mostraremos cómo el concepto 'humedales' es disputado por diferentes agentes sociales en la arena pública. Finalmente, mostraremos los conflictos suscitados a partir de las formas en que estos conceptos fueron definidos en las leyes bajo estudio, y reflexionaremos sobre las consecuencias políticas de aquello que se ha caracterizado como 'la condición post-política' (Swyngedouw 2011).

\section{Materiales y MÉTOdos}

La metodología que utilizamos en este trabajo fue primordialmente cualitativa (Penalva Verdú et al. 2015). Esta investigación se llevó adelante, en primer lugar, a través de un análisis documental focalizado en los documentos estatales, como los proyectos de ley, los dictámenes de las comisiones legislativas y las versiones taquigráficas de los debates en las Cámaras de Senadores y Diputados de la Nación (Muzzopappa and Villalta 2011). También se analizaron los diferentes documentos escritos producidos por los científicos que participaron en los diferentes momentos de las dos políticas públicas bajo análisis. Para ello, los posicionamientos y argumentaciones de los agentes participantes en una disputa fueron interpretados como discursos que expresan un sentido construido en determinados contextos (políticos y sociales) y para determinados destinatarios y fines, cuyas marcas se pueden rastrear (Vera Alpuche 2012).

Este análisis fue complementado con la producción de datos cualitativos a través de técnicas etnográficas, como la observación participante y las entrevistas en profundidad (Guber 2001). Se llevaron a cabo instancias de observación en 5 debates públicos sobre las temáticas analizadas, 6 encuentros de asambleas, 8 festividades en las que representantes de organizaciones locales expresaron públicamente sus posturas sobre estas leyes, 6 seminarios abiertos de equipos de investigación que participaron en estos procesos y 3 presentaciones de publicaciones escritas producidas por científicos. Los registros fueron transcriptos e incorporados al corpus de análisis. Además, entre 2012 y 2019 realizamos 50 entrevistas en profundidad a 13 científicos, 12 funcionarios y técnicos de agencias estatales vinculadas a lo ambiental, 9 funcionarios y técnicos de otras agencias estatales vinculadas al desarrollo rural, 1 legislador nacional y 15 representantes de asambleas y organizaciones locales. En todos los casos se trabajó con una guía mínima de temas, procurando respetar los principios de no-directividad del investigador y libre asociación del informante y evitando imponer los marcos interpretativos propios (Guber 2001). Los registros producidos mediante esta técnica también fueron incorporados al corpus, sobre el cual se aplicó luego un análisis de contenido. La representatividad de la muestra, por su parte, fue evaluada en términos teóricos y no probabilísticos, en función de su pertinencia para dar cuenta de los objetivos de la investigación (Guber 2001).

Para el caso de la "Ley de Glaciares", el análisis realizado abarca desde 2008 hasta 2018. De esta forma, nos proponemos incluir en nuestro trabajo tanto la primera sanción de la Ley y su posterior veto (2008-2010) como la segunda sanción y su implementación (2010-2018). Para el caso de la "Ley de Humedales", nuestro estudio abarca el mismo período histórico y comprende todo el proceso de institucionalización de la norma, desde la formulación de los anteproyectos de ley (2010) hasta la pérdida de estado parlamentario a fines de 2018, incluyendo los debates parlamentarios ocurridos en 2013 y 2016.

\section{Resultados}

\section{La "Ley de Glaciares"}

En 2008, la Ley Nacional 26418 de Presupuestos Mínimos para la Preservación de los Glaciares y el Ambiente Periglacial fue sancionada unánimemente por el Congreso Nacional. Pocas semanas después, el Poder Ejecutivo la vetó a través del Decreto 1837/ 2008, bajo el argumento de que afectaba la competencia de las provincias y que sus prerrogativas podrían afectar el desarrollo 
económico de las provincias cordilleranas por la prohibición de la actividad minera o petrolífera en ciertos espacios. Para algunos sectores vinculados con ONG ambientalistas, este veto estuvo impulsado por la presión del sector minero, en especial de la empresa multinacional Barrick Gold, que poseía los emprendimientos más importantes de la provincia de San Juan. Por ese motivo, el veto fue caracterizado en la agenda pública como "Veto Barrick Gold" (Isla Raffaele 2015).

Sin embargo, el incremento de la presión social para sancionar la Ley favoreció el acuerdo entre legisladores que impulsaban distintos proyectos. Así, en los dos años que siguieron al veto, se profundizó el debate sobre cómo proteger a los glaciares y el ambiente periglacial ante el avance de la actividad minera (Isla Raffaele 2017). En este período, el principal punto de discusión fue qué debía entenderse por 'ambiente periglacial': esto era de fundamental importancia, dado que afectaba la delimitación del área hasta donde podría extenderse la actividad minera en la Cordillera de los Andes.

La discusión se cristalizó en la formulación de dos proyectos diferentes (Isla Raffaele 2015). Uno de ellos retomaba el texto de la ley vetada, establecía la protección de todo el ambiente periglacial y lo definía como el "área de alta montaña con suelos congelados que actúa como regulador del recurso hídrico". El otro, en cambio, extendía la protección dentro del ambiente periglacial sólo a los glaciares de escombros, entendiendo que estos cumplían la función de reserva hídrica, y los conceptualizaba como "cuerpos de detrito congelado y hielo, cuyo origen está relacionado con los procesos criogénicos asociados con suelo permanentemente congelado y con hielo subterráneo, o con el hielo proveniente de glaciares descubiertos y cubiertos". Si bien esta segunda definición había sido elaborada pensando en la posterior realización del Inventario de Glaciares, fue criticada por ser menos protectora: se afirmaba que incluía sólo una parte del ambiente periglacial como bien jurídico tutelado, y que se permitiría la actividad minera en varios de estos espacios (Iud 2011). Así, los debates en torno a la definición del objeto a proteger evidencian el carácter político de una categoría que podríamos caracterizar como técnica.

Al igual que como sucedió en el proceso de sanción de la "Ley de Bosques" (Ley 26.331 de Presupuestos Mínimos de Protección
Ambiental de los Bosques Nativos) a nivel nacional (Langbehn 2016), diversos agentes sociales participaron en el campo de fuerzas en que se dirimía la sanción de la "Ley de Glaciares". Por una parte, asambleas socioambientales, ONG ambientalistas y expertos vinculados con cuestiones ambientales se manifestaron públicamente a favor de la sanción y movilizaron sus dotaciones de capital cultural y social en pos de dicho objetivo (Isla Raffaele 2015; Rojas and Wagner, en prensa). Contrariamente, sectores ligados a la minería metalífera a gran escala que se realiza en zonas cordilleranas se opusieron y activaron diversos mecanismos de presión sobre los tomadores de decisión (Isla Raffaele 2016). Los mecanismos de presión (esto es, el lobby) son una de las principales estrategias desarrolladas por los agentes sociales con mayores dotaciones de capital económico y político, especialmente en sus intentos por retrasar la sanción de políticas ambientales o restringir sus ámbitos de aplicación.

En este período, ciertas provincias que consideraban que la "Ley de Glaciares" podría comprometer el desarrollo de la actividad minera en sus territorios sancionaron sus propias leyes provinciales de protección de glaciares; así lo hicieron San Juan, Jujuy, Salta, La Rioja y Santa Cruz. Estas leyes constituyeron una forma de rechazo a las discusiones parlamentarias que se estaban realizando a nivel nacional, y fueron aprobadas rápidamente sin debates en comisiones ni consultas a profesionales (Sede 2011). Además de crear inventarios de glaciares a cargo de instituciones provinciales y de no prohibir explícitamente la minería, dichas normas adoptaban las definiciones del proyecto caracterizado como menos proteccionista y reducían aún más el área a proteger, al conservar únicamente los glaciares de escombros activos y excluir a los inactivos (Isla Raffaele 2015). De esta forma, mediante estas leyes se pretendía evitar (o cuanto menos retrasar) la intervención nacional sobre los glaciares, delegar su evaluación y monitoreo a las autoridades provinciales (Bottaro and Sola Álvarez 2018), y obstaculizar la implementación de la Ley nacional. Si bien la legislación provincial debía posteriormente adecuarse a los lineamentos definidos en la legislación nacional, la contradicción entre los dos marcos normativos de protección de glaciares favoreció la ocurrencia de procesos de judicialización que les permitió a las empresas mineras continuar con su actividad 
extractiva durante más tiempo que el previsto por la ley oportunamente sancionada (Sede 2011), tal y como sucedió en las provincias de San Juan y Jujuy (Isla Raffaele 2015).

El30 de septiembre de 2010, el Senado aprobó la "Ley de Glaciares" por un estrecho margen de tan sólo dos votos. En dicha votación, el $60 \%$ de los votos en contra correspondieron a legisladores de provincias mineras pertenecientes a distintos partidos políticos (Ryan 2014): como afirma Packmann (2014: 11), "los intereses de provincias relacionadas con la minería se opusieron a la sanción de una ley que les resultaba potencialmente peligrosa con respecto a sus objetivos de promover una actividad productiva".

La LN 26639 de Presupuestos Mínimos para la Preservación de los Glaciares y el Ambiente Periglacial estableció los lineamientos básicos para la protección de este tipo de ecosistemas, con el objeto de preservarlos como reservas estratégicas de recursos hídricos para diversos usos (consumo humano, actividades agrícolas, recarga de cuencas hidrográficas, o protección de la biodiversidad), como atractivo turístico y como fuente de información científica (art. 1). A su vez, se determinó que los glaciares constituirían bienes de carácter público, lo que implica que se encontrarían afectados al uso general o al servicio público, y no a fines privados (Bottaro and Sola Álvarez 2018).

En el art. 2 de la Ley se definió el sentido de los conceptos 'glaciar' y 'ambiente periglacial'. El alcance del área definida como 'ambiente periglacial', como se comentó anteriormente, fue uno de los puntos de mayor controversia en los debates parlamentarios: mientras algunos habían abogado por la importancia de proteger a todo el ambiente periglacial, otros afirmaban que únicamente los glaciares de escombros debían ser incluidos en dicha categoría. Finalmente, con el fin de evitar que se dilatase aún más el debate y se permitiese el avance de la minería, se llevó a cabo un acuerdo político entre ambas posturas que resultó en un nuevo texto que tomó aportes de los proyectos en discusión, pero donde predominaron las disposiciones del proyecto más proteccionista, con el objetivo de lograr consenso con respecto a las zonas a preservar y sancionar la Ley (Isla Raffaele 2015). Así, la Ley definió al ambiente periglacial de alta montaña como el "área con suelos congelados que actúa como regulador del recurso hídrico", e incorporó la zona de baja y media montaña, definiendo al ambiente periglacial en dicha altura como el "área que funciona como regulador de recursos hídricos con suelos saturados en hielo" (art. 2). Por su parte, los glaciares fueron definidos como una "masa de hielo perenne estable o que fluye lentamente, con o sin agua intersticial, formado por la recristalización de nieve, ubicado en diferentes ecosistemas, cualquiera sea su forma, dimensión y estado de conservación", considerado también como parte constitutiva del glaciar al material detrítico rocoso y los cursos internos y superficiales de agua (art. 2).

En el art. 3 de la Ley se definió la creación de un Inventario Nacional de Glaciares (ING). Allí debían individualizarse todos los glaciares y geoformas periglaciales que actúan como reservas hídricas, y debía actualizarse cada 5 años con el fin de monitorear los cambios de superficie que pudiesen producirse (art. 4). Aunque indirectamente se incluía en la "Ley de Bosques" (dado que el ordenamiento territorial presuponía la realización de un inventario), la "Ley de Glaciares" constituye la primera norma de presupuestos mínimos en que la creación de un inventario se incorpora de manera explícita como una de las etapas del proceso de categorización. Si bien esta herramienta no está formalmente incluida en la Ley General del Ambiente, se trata de un insumo clave para diversos instrumentos de políticas ambientales, como el ordenamiento ambiental del territorio o la producción de un sistema de diagnóstico e información ambiental. Por lo tanto, no es extraño que esta herramienta haya sido luego incluida en todos los proyectos de ley de presupuestos mínimos presentados posteriormente.

La realización del ING, de acuerdo con el art. 5, fue encomendada a una Unidad Ejecutora del CONICET: el Instituto Argentino de Nivología, Glaciología y Ciencias Ambientales (IANIGLA). La coordinación, por su parte, fue asignada a la Secretaría de Ambiente y Desarrollo Sustentable de la Nación (SAyDS), en tanto autoridad de aplicación. Si bien en los debates parlamentarios se cuestionó la falta de espacios de participación de las provincias en la construcción del ING y se argumentó que esto podría comprometer al federalismo, finalmente prevaleció el criterio de que sea una única institución científica la encargada de llevar a cabo esta tarea. Esto podría explicarse, entre otros factores, por las experiencias previas vinculadas con la "Ley de Bosques". Cabe señalar que en esa ocasión el proceso de Ordenamiento Territorial de 
los Bosques Nativos (OTBN) fue realizado por cada provincia de forma individual, pero sólo cuatro de ellas lo realizaron en tiempo y forma (MAyDS 2016). Además, se detectaron inconsistencias entre provincias limítrofes que limitaban fuertemente la consecución de los objetivos de protección de las masas remanentes de bosques nativos (García Collazo et al. 2013), y en la gran mayoría de los casos los procesos de construcción de los OTBN provinciales estuvieron signados por situaciones de conflicto entre diversos agentes sociales. Frente a este escenario, en la "Ley de Glaciares" se definió que el ING sería realizado por una única institución, de manera tal de asegurar la uniformidad de criterios de identificación y demarcación de los glaciares y el ambiente periglacial a lo largo de toda la Cordillera. Y, al mismo tiempo, esto permitiría evitar posibles demoras que podrían producirse en las provincias que habían ofrecido mayor resistencia a la sanción de la Ley.

Sin embargo, esta decisión también generó diversos inconvenientes. Por un lado, la centralización del inventario supuso la apertura de un frente de conflictos con las provincias. Por otro lado, y a diferencia de lo sucedido en la "Ley de Bosques", la participación ciudadana no estaba incluida en el proceso (con excepción de la realización de evaluaciones de impacto ambiental de cualquier nueva actividad que se emplazara sobre zonas de glaciares o ambientes periglaciales). Es decir, en el caso de la "Ley de Bosques" el componente técnico era uno de los elementos del proceso de OTBN, pero no el único: la definición participativa de los criterios de categorización de los bosques y las audiencias públicas obligatorias, aún con sus limitaciones, evidenciaba de formas más claras el carácter político del proceso de ordenamiento del territorio. Por el contrario, al no incluir la participación ciudadana, la producción del ING se presentaba como un proceso eminentemente técnico. Sin embargo, al identificar y delimitar los glaciares, el inventario determina las formas de uso y apropiación de esos ecosistemas, dado que la Ley ya estaba definido qué actividades podrían realizarse en esas zonas específicas. Por lo tanto, aun cuando se presente como meramente técnico, su carácter político sigue estando presente. Y aunque dicha caracterización del proceso invisibiliza esta dimensión, ésta siempre termina emergiendo. De hecho, como reconocen Rojas y Wagner (en prensa), el proceso de sanción de la Ley de
Glaciares tuvo una participación social muy grande, pero la Ley no previó mecanismos que institucionalizaran esa participación en la fase de implementación y esto intensificó los cuestionamientos realizados posteriormente al ING.

Para lograr sus objetivos de preservación de los glaciares y el ambiente periglacial, la "Ley de Glaciares" estableció la prohibición de ciertas actividades, como las industriales o las mineras e hidrocarburíferas, así como todas aquellas que supusieran la liberación de sustancias contaminantes (art. 6). La inclusión de la actividad minera dentro de este artículo fue una de las cuestiones que generó mayor polémica en torno a la "Ley de Glaciares", y aquellos agentes vinculados con la megaminería que habían apoyado el veto presidencial en el año 2008 impusieron medidas cautelares en San Juan y Jujuy y favorecieron los procesos de juridificación de la Ley (Isla Raffaele 2016). Esto, además, retrasó la realización del ING en dichas provincias, ya que hasta que la Corte Suprema de Justicia de la Nación no resolvió las demandas (en ambos casos favorablemente a la Ley nacional), no pudieron comenzar las tareas del inventario en esas jurisdicciones.

Luego de sancionada la Ley, las definiciones de los bienes a proteger continuaron siendo foco de controversias: de hecho, la situación derivó en un proceso judicial en el cual resultaron procesados funcionarios de la SAyDS y del IANIGLA. En cumplimiento con el art. 15 de la Ley de Glaciares, el Instituto elaboró un cronograma de ejecución del inventario en el que estableció los objetivos, la metodología y plazos a cumplir (IANIGLA 2010). Pero, además, introdujo nuevos elementos a las definiciones de 'glaciar' y 'ambiente periglacial' a los fines "específicos y operativos" del ING y delimitó el tamaño mínimo que debía tener una geoforma para ser incorporada al inventario (siendo éste 1 hectárea). A su vez, determinó un periodo mínimo de visibilidad de 2 años para los glaciares e incorporó al inventario a los manchones de nieve permanentes, debido a su importancia como reservas de agua en estado sólido. El objetivo de realizar esas redefiniciones de las categorías en cuestión era "aclarar las características básicas de los diferentes cuerpos a reconocer en las imágenes satelitales y los procesos que las originan, para que puedan ser identificados y reconocidos por los operadores sin lugar a ambigüedades" (IANIGLA 2010: 20). En el documento, 
el IANIGLA informó que sostendría una conceptualización amplia de la categoría 'ambiente periglacial' pero restringiría el inventario únicamente a los glaciares de escombros, argumentando que constituyen las geoformas con mayor contenido de hielo y que podrían ser identificadas y delimitadas técnicamente. Dicha metodología fue aprobada por la SAyDS y por la Jefatura de Gabinete de Ministros de la Nación, y en base a ese documento se reglamentó la norma. Esa decisión, que se tomó con el fin de poder realizar el inventario en tiempo y forma, supuso una reconceptualización de estas categorías, y pese a que se anclaba en un argumento de carácter técnico traería aparejadas consecuencias significativas en términos políticos (y también jurídicos).

Como parte de una serie de entrevistas realizadas en 2014 a distintos agentes, uno de los científicos que participó del proceso afirmó que ese documento les permitió "comenzar a trabajar con una base científica y no una base política", ya que para ellos las nociones de baja, media y alta montaña eran muy subjetivas. Y es que para los miembros del IANIGLA, el texto resultante de la Ley no había establecido definiciones "técnicas" $y$, por tanto, fue necesario hacer una interpretación de su sentido y determinar qué era lo que se debía proteger. El modo de enunciación de estas afirmaciones, destacando el carácter "técnico" del proceso y señalando la importancia de las "bases científicas", refleja uno de los dispositivos a través de los cuales operan los procesos de despolitización de ciertas categorías, dado que se trata de presentar esta cuestión por fuera del espacio de la disputa pública y la contestación, en los términos de Swyngedouw (2011). Cabe aclarar, sin embargo, que esto no implica asignarle intencionalidad al científico en sí mismo. Los procesos de despolitización de "lo natural" y "lo técnico" lo (nos) exceden largamente: son un dispositivo de la gubernamentalidad medioambiental, y nuestras propias subjetividades son constituidas en ese universo de sentido hegemónico (Straccia and Pizarro 2017). Otro de los científicos entrevistados reconoció las diferencias en torno a las definiciones a utilizar, pero se focalizó en los objetivos que se perseguían con la sanción de la Ley, al señalar que "hubo una disputa por la Ley, que resultó una mezcla y no quedó tan claramente establecido (...) Pero IANIGLA sí tenía bien claro dónde estaban esas reservas hídricas y qué había que proteger". Si bien a partir de estas discusiones se llegó a un consenso técnico (entre ciertos agentes específicos) sobre qué sería el ambiente periglacial y cómo se relevarían los glaciares y el ambiente periglacial, su carácter político y la inestabilidad de los consensos producidos se hizo visible algunos años después.

Esto se hace en particular evidente al analizar lo sucedido a partir de 2015, momento en el que se inició el segundo proceso de juridificación de la "Ley de Glaciares". Luego de los derrames de cianuro ocurridos en la mina Veladero (explotada por Barrick Gold) en San Juan, la Asamblea 'Jáchal No Se Toca' y la Asociación de Abogados Ambientalistas de la Patagonia presentaron una serie de demandas a la empresa, funcionarios provinciales y nacionales. Como consecuencia de estas denuncias la empresa fue multada por el derrame y nueve operarios fueron procesados, pero la responsabilidad de los funcionarios provinciales y de los directivos de la empresa no fue investigada. En cuanto a los funcionarios nacionales, tres secretarios de ambiente y el exdirector del IANIGLA fueron procesados y elevados a juicio por incumplimiento de la Ley. En los argumentos del procesamiento se acusó al IANIGLA de emplear criterios y definiciones que violaban el texto de la Ley, de realizar interpretaciones incompletas de su espíritu y de reducir el área de conservación. Consecuentemente, los exfuncionarios de la SAyDS y el exdirector del IANIGLA fueron procesados por el delito de abuso de autoridad, al considerar que incumplieron con lo establecido por la "Ley de Glaciares" y con los plazos de ejecución del ING. Esto último podría deberse a diversos factores, pero sin duda uno de ellos fue la dificultad para conseguir el financiamiento necesario, dado que esta Ley (a diferencia de lo ocurrido en la "Ley de Bosques") no creó un fondo destinado a costear la realización del inventario (Maffei 2010).

En paralelo a estos procesamientos, a fines de 2016 se hizo público un documento del Gobierno Nacional donde se señalaba que se pretendía modificar la reglamentación de la "Ley de Glaciares", en un sentido que favorecería a las empresas mineras. Entre otros aspectos, se proponía que para que un glaciar de escombros sea protegido por la Ley debía comprobarse su significancia hídrica, y que ello sería evaluado por las autoridades ambientales provinciales. Hasta el momento, sin embargo, esta modificación no ha prosperado. 
Finalmente, en mayo de 2018 se presentó oficialmente el resultado final del inventario, hecho que convirtió a la Argentina en el único país en el mundo en tener un registro de sus glaciares y zonas periglaciales (IANIGLA 2018). Sin embargo, las controversias en torno al mismo continúan. Por un lado, algunos sectores vinculados con ONG ambientalistas denunciaron que el ING "está correcto, pero incompleto" por estar ausentes los glaciares menores a una hectárea. Por otro lado, desde la SAyDS continúan avalando el criterio técnico que utilizó el IANIGLA y anunciaron que le solicitarán al Congreso que se expida acerca de la superficie mínima que debe contemplar la "Ley de Glaciares".

De esta forma el proceso de sanción e implementación de la "Ley de Glaciares" estuvo marcado por la continua emergencia del carácter político de dos categorías centrales: 'glaciar' y, 'ambiente periglacial'. Aun cuando se sostenga que su definición responde a características técnicas/científicas, supuestamente 'naturales' y, por tanto, apolíticas (en sintonía con las características propias de los procesos de despolitización, señaladas previamente), dichas categorías devienen objeto de importantes disputas entre sectores con diferentes intereses al ser utilizadas en la formulación e implementación de políticas de gestión ambiental. Así, su dimensión política gana fuerza en la arena pública y se hace evidente que exceden los límites de lo técnico-científico y se extienden a las discusiones por el desarrollo de la actividad minera y, más ampliamente, a las disputas por la definición de los regímenes de apropiación de la naturaleza (Isla Raffaele 2019).

\section{La "Ley de Humedales"}

Si en la sección anterior hemos visto que el avance de la actividad minera en la zona cordillerana fue un factor que explicó la formulación de una política orientada específicamente a la protección de los glaciares, múltiples conflictos ambientales en los humedales del Delta del Río Paraná fueron el puntapié para empezar a pensar en una Ley nacional de conservación de humedales, de acuerdo con algunos de los científicos que asesoraron a los legisladores nacionales en el proceso de formulación de la Ley, y a quienes entrevistamos en el transcurso de 2016. En un contexto de creciente conflictividad en torno a lo ambiental, vinculado especialmente al avance de la agricultura extensiva y los mega-emprendimientos inmobiliarios, diversas ONG conservacionistas comenzaron a reclamar la necesidad de regular las formas de uso y apropiación de los recursos en los humedales. Si bien en la década del 2000 comenzaron a formularse políticas específicas orientadas al ordenamiento de estos ecosistemas, el científico entrevistado sostuvo que "el hecho de que existieran algunas [otras] leyes [de presupuestos mínimos] sirvió como espaldarazo para que nos pusiéramos a pensar que para humedales también teníamos que hacer lo mismo". Así, comenzó a ganar fuerza esta posibilidad.

Dichas ONG comenzaron a impulsar la formulación de un anteproyecto de "Ley de Humedales" en 2010. Senadores de dos partidos políticos diferentes comenzaron a trabajar con equipos técnicos pertenecientes a distintas ONG y Universidades Nacionales, y en 2013 dos anteproyectos distintos fueron presentados. Sin embargo, ambos proyectos concordaban en la mayor parte de su contenido y fueron unificados en las comisiones legislativas, aun cuando tenían algunas diferencias menores entre sí (Monkes 2017). A fines de 2013 el proyecto unificado fue debatido y aprobado por unanimidad en la Cámara de Senadores de la Nación.

El Proyecto de Ley de Presupuestos Mínimos para la Conservación, Protección, Restauración Ecológica y Uso Racional y Sostenible de los Humedales aprobado retomaba los lineamentos que plantea la Convención Ramsar (a los cuales nuestro país había adherido mediante la LN 23919 en el año 1991), puesto que remarcaba la importancia de la "conservación, protección, restauración ecológica y uso racional y sostenible" de estos ecosistemas (art. 1). Según el art. 2, de acuerdo con lo planteado en esa misma Convención, serían considerados humedales "las extensiones de marismas, pantanos y turberas, o superficies cubiertas de aguas, sean éstas de régimen natural o artificial, permanentes o temporales, estancadas o corrientes, dulces, salobres o saladas, incluidas las extensiones de agua marina cuya profundidad en marea baja no exceda de seis metros".

Esta definición, sumamente amplia, fue señalada como problemática por representantes de otras instituciones estatales, como el Consejo Hídrico Federal (CoHiFe). Según algunos de los asesores que impulsaron este proyecto de Ley, existen diferentes definiciones de 'humedal' ("algunas más técnicas, otras más operativas") 
y la superficie de humedales a inventariar variaría sustantivamente dependiendo de la definición que se seleccione. Entonces, la definición a utilizar en la Ley no sería un detalle menor: nuevamente, y como mostraremos a continuación, se trata de la emergencia del carácter político de una categoría despolitizada.

Asícomo en la "Ley de Glaciares" la definición de la categoría 'ambiente periglacial' respondió esencialmente a acuerdos políticos entre los legisladores, la definición de 'humedal' en el marco de la "Ley de Humedales" se debió a cuestiones legales señaladas por los abogados que asesoraban a los legisladores. Y es que, independientemente de su operatividad o su (falta de) rigurosidad científica, se sostenía que en términos legales era excluyente retomar lo planteado por la Convención Ramsar. Sin embargo, uno de los científicos entrevistados reconocía que luego de la media sanción el problema seguía sin estar resuelto, dado que la definición universalizante incluida en la Ley no se correspondía "con puntos de vista estrictamente científicos", desde su parecer.

El Proyecto de "Ley de Humedales" tenía una estructura muy similar a la "Ley de Glaciares" y a otras leyes de presupuestos mínimos previas. En su art. 5 proponía la construcción de un Inventario Nacional de Humedales (INH), que sería coordinado por la autoridad nacional de aplicación, pero en articulación con las provincias y con la asistencia de diversos organismos científicos del país, así como su actualización periódica cada cinco años. Además, delegaba en las provincias la clasificación de los humedales en alguna de las tres categorías definidas (preservación, restauración o manejo sostenible, según el art. 9), esto es, el ordenamiento ambiental del territorio. De este modo, la "Ley de Humedales" buscaba posicionarse en un lugar intermedio entre las distintas leyes de presupuestos mínimos sancionadas previamente. En el caso de la "Ley de Bosques", tanto el inventario (esto es, la definición de qué superficies serían categorizadas) como el posterior OTBN fueron procesos en los que los organismos técnico-científicos participaron, pero no de modo excluyente: la participación ciudadana, a través de diferentes mecanismos, estaba comprendida. En el caso de la "Ley de Glaciares", el ING se centralizó en un único organismo técnico-científico considerado legítimo y no previó instancias de participación social. La "Ley de Humedales", por lo tanto, se posicionaba en un punto intermedio, dado que la producción del INH sería nacional (al igual que en la "Ley de Glaciares") pero en articulación con las provincias; sin embargo, continuaba sin incluir mecanismos de participación de ciudadana en esta instancia. El ordenamiento territorial de los humedales comprendidos en el INH, en cambio, sí sería un proceso provincial, al igual que en la "Ley de Bosques". Los mecanismos de participación ciudadana, sin embargo, no se aplicarían al proceso de categorización, sino que estarían restringidos a las evaluaciones de impacto ambiental de nuevas obras de infraestructura y actividades humanas (art. 8), tal como prevé la Ley General del Ambiente. En otras palabras, los argumentos técnico-científicos -al igual que en la "Ley de Glaciares" - continuaban siendo la fuente de legitimación que definía quiénes podrían participar y quiénes no en estas definiciones.

Independientemente de estas cuestiones, el punto más acuciante de la Ley continuaba siendo la disputa en torno a cuál sería la definición más apropiada de 'humedal'. Como indicamos, algunos agentes reproducían elementos de sentido del discurso jurídicolegal para afirmar la importancia de replicar la contenida en la Convención Ramsar. Otros, en cambio, cuestionaban que ésta no tenía un carácter operativo y que su excesiva amplitud impediría la realización del inventario, de modo que apelaban a elementos de sentido del discurso biológico-ecológico para especificar qué características debía cumplir un área para ser considerada 'humedal' y señalar que la presencia de vegetación hidrofítica y suelos hídricos o con rasgos de hidromorfismo eran las características diagnósticas comunes que permitirían reconocerlo. De este modo, el carácter político de un concepto escurridizo e inconsistente, en los términos de Morton (2007), continuó emergiendo en cada una de las diversas presentaciones que realizaron distintos científicos señalando qué superficie del territorio nacional se vería afectada por la Ley: algunos sostenían que se inventariaría y clasificaría el 11\% de la superficie; otros, en cambio, afirmaban que sería el $25 \%$. De este modo, la dimensión política de esta categoría se hizo evidente desde las instancias iniciales del proceso de formulación de la Ley, y por tanto no puede ser soslayada.

Pese al impulso dado por la aprobación unánime en la Cámara de Senadores a fines de 2013, a mediados de 2014 algunas voces comenzaron a expresar su preocupación por la falta de tratamiento de este proyecto 
en las respectivas comisiones de la Cámara de Diputados. Hacia fines de 2015, las ONG conservacionistas difundieron públicamente un comunicado dirigido a las Comisiones de la Cámara de Diputados en el que exigían "que hagan posible el tratamiento y la aprobación de la Ley de Humedales". Pese a estas presiones, el proyecto de ley no recibió dictamen en dos de las tres comisiones asignadas en el período de sesiones ordinarias y, finalmente, en diciembre de 2015 perdió estado parlamentario. Esto se habría vinculado, entre otras cosas, con la presión realizada por los responsables de los mega-emprendimientos inmobiliarios, cuyo estrecho vínculo con la presidenta de una de las Comisiones de la Cámara favoreció que el proyecto nunca fuera tratado (Monkes 2017)

Sin embargo, en 2016 esta temática surgió nuevamente en la agenda legislativa, luego de que el Presidente de la Nación aprovechara un evento realizado por el Día Internacional de los Humedales para señalar la importancia de tener una normativa de protección y conservación de estos ecosistemas. En los meses subsiguientes se presentaron nuevamente los mismos proyectos de ley, y entre septiembre y noviembre de 2016 una Comisión Mixta conformada por la Comisión de Agricultura y la Comisión de Ambiente y Recursos Naturales llevó adelante múltiples audiencias a fin de elevar un dictamen en relación con esta ley, la cual obtendría media sanción a fines de ese año (Monkes 2017).

Allí, nuevamente, los debates sobre cómo definir la categoría 'humedal' ocuparon un rol central. Si bien en el proyecto original se proponía replicar la definición contenida en la Convención Ramsar por los motivos señalados previamente, las instituciones estatales que participaron en las audiencias, como CoHiFe, CoFeMA (Consejo Federal de Medio Ambiente) e INTA (Instituto Nacional de Tecnología Agropecuaria), cuestionaron abiertamente "la falta de una definición propia". Finalmente, el consenso técnico-científico entre estas instituciones y el consenso político entre los legisladores favoreció el establecimiento de una nueva definición de 'humedal', más acorde con la explicitación de las características biofísicas de estos ecosistemas. Así, el proyecto de Ley sancionado afirma en su art. 2 que, "a los fines de la presente ley, entiéndase por humedales a los ambientes en los cuales la presencia temporaria o permanente de agua superficial o subsuperficial causa flujos biogeoquímicos propios y diferentes a los ambientes terrestres y acuáticos. Rasgos distintivos son la presencia de biota adaptada a estas condiciones, comúnmente plantas hidrófitas, o suelos hídricos o sustratos con rasgos de hidromorfismo". Recordemos que la normativa sería aplicable sobre espacios donde agentes sociales muy diferentes entre sí (desde pescadores hasta empresarios inmobiliarios o mineros) llevan adelante sus actividades productivas y de vida. Dado que la decisión sobre qué definición se utiliza modifica de manera sustantiva la superficie del territorio nacional que sería inventariada como humedal, el carácter político de dicha definición emerge: se trata, una vez más, de la emergencia del carácter político de una categoría despolitizada, en el devenir del proceso de producción de una normativa ambiental.

Además, hubo un segundo elemento que fue debatido en el recinto y que refleja el carácter político de los procesos de conservación de la naturaleza. En el proyecto original no se especificaba qué humedales se inventariarían, y se sugería que serían únicamente aquellos definidos como "de relevancia" por cada jurisdicción. En estas audiencias, las instituciones estatales participantes sostuvieron que el inventario debía realizarse sobre todos los humedales, de acuerdo "con criterios técnicos", y no sólo sobre aquellos definidos como relevantes. Finalmente, el art. 5 de la "Ley de Humedales" reflejó estas posturas y estableció la creación del "Inventario Nacional de Humedales (INH), donde se identificarán los humedales de todo el territorio de la Nación". Sin embargo, pese a que diversos agentes con intereses disímiles participación en el proceso que culminó con media sanción de la Ley, una vez más ésta no fue tratada por la Cámara de Diputados $\mathrm{y}$, nuevamente, perdió estado parlamentario a fines de 2018.

Así, el análisis del proceso de formulación de la "Ley de Humedales" (cuya sanción continúa siendo demandada por una amplia gama de agentes sociales, tanto académicos como no académicos) pone de manifiesto los modos en que emerge la dimensión política de la categoría 'humedal'. Dada la sustancial diferencia en superficie afectada por la Ley según una u otra definición, ésta deviene objeto de disputas entre los agentes sociales participantes en este proceso. De hecho, los Senadores del NOA cuestionaban que se utilizara una definición amplia de 'humedal', dado que incluiría a los salares de altura y 
restringiría a actividades productivas como la extracción de Litio, y recién acompañaron al proyecto de Ley en el 2016 cuando se incorporó un artículo adicional que excluía explícitamente a dichos salares del INH. De este modo, y al igual que en lo referido a la "Ley de Glaciares", sostenemos que las definiciones bajo disputa exceden los límites de lo técnico-científico y refieren a discusiones sobre cuáles son las formas más adecuadas de uso y apropiación de la naturaleza.

\section{Discusión}

Hace algunos años se produjo un enriquecedor debate en esta revista. Gurvich et al. (2009), reflexionando sobre el rol de los ecólogos ante la crisis ambiental moderna, sostuvieron que "[los científicos,] en un 'mundo ideal', sólo investigaríamos, y otros individuos o instituciones serían los encargados de transferir la información generada a los políticos, funcionarios y sector privado" (op. cit.: 236). En esta afirmación, los imaginarios de una ciencia neutral y por fuera de la política se hacen evidentes. Paruelo (2009), en respuesta a dicho artículo, alertó que la idea del consenso ganaba prestigio día tras día, pero que esto no supondría fijar una posición común sino identificar los disensos. También señaló que, si bien "debemos reclamar que nos escuchen, que nos den lugar como actores importantes en el preso de toma de decisiones (...) [tampoco] convendría ser ingenuos: las decisiones se toman en la arena política" (op. cit.: 258), y sostuvo la necesidad de reconocerse(nos) como científicos movidos por valores e intereses que luchan por ideales sobre cómo deberían ser las cosas. En este trabajo hemos profundizado sobre las disputas que se producen al procurar prescribir formas de uso y apropiación de la naturaleza, poniendo de manifiesto el carácter político de las categorías 'glaciar', 'ambiente periglacial' y 'humedal' en el devenir de los procesos de institucionalización de la "Ley de Glaciares" y la "Ley de Humedales".

El análisis realizado evidenció dos cuestiones. Por un lado, que no existe una definición unívoca para cada una de estas categorías. Las categorías asociadas al dominio de "lo natural" también refieren a construcciones sociales, y el supuesto consenso en torno a qué representaría cada una de ellas no es más que un síntoma de la imposición de ciertas racionalidades y de su despolitización (Swyngedouw 2011). Cuando dichas categorías son puestas en juego en la arena política, su repolitización favorece la emergencia de diversas definiciones y de disputas sobre cuál sería la más apropiada (De la Vega 2017), aún entre agentes sociales cuyos objetivos de conservación son similares. En otras palabras, el consenso no es más que un disenso estabilizado y es siempre contingente; por lo tanto, las reconfiguraciones en cada uno de estos campos de fuerza podrán facilitar la reemergencia de dichas diferencias. Estas afirmaciones no suponen negar la búsqueda del consenso como horizonte, sino que reconocen que éste no depende exclusivamente de cuestiones técnicas y asumen su inestabilidad como un elemento constituyente (es decir, reconocen su carácter político). Por otro lado, se evidencia también la existencia de intereses diversos y contrapuestos asociados a los agentes que apoyan cada una de las posibles definiciones. Así, los debates por las leyes reactivaron conflictos vinculados con importantes actividades económicas (megaminería o megaemprendimientos inmobiliarios, por ejemplo), los cuales, a su vez, traspasaron la escala de lo local o provincial y comenzaron a ser discutidos a nivel nacional y en la esfera legislativa. Las discusiones sobre cómo definir 'glaciar', 'ambiente periglacial' o 'humedal', entonces, no responden únicamente a un debate conceptual sino también político sobre cuáles regímenes de apropiación de la naturaleza buscamos favorecer.

El proceso de institucionalización de la "Ley de Glaciares" (que ha atravesado dos sanciones, un veto presidencial y sucesivos procesos de judicialización) pone de manifiesto que en las disputas sobre qué es un 'glaciar' o el 'ambiente periglacial' subyace un debate sobre la megaminería, las actividades extractivas y los modelos de desarrollo que debería perseguir el país. Así, el sector minero llevó adelante continuas presiones para evitar la sanción, favorecer el veto y obstaculizar el trabajo del IANIGLA en la producción del ING, a través del ejercicio de lobby y la judicialización del conflicto. Por su parte, los sectores ambientalistas presionaron para que la Ley fuera sancionada, cuestionaron el criterio con que el IANIGLA llevó adelante el proceso del inventario, y también desarrollaron estrategias judiciales. Estas posiciones contrapuestas favorecen los procesos de contestación y disputa de estas categorías en la arena pública, y ponen de manifiesto su carácter esencialmente político. 
Un proceso similar puede observarse en el proceso de institucionalización de la "Ley de Humedales". Aun cuando se trata de un proceso todavía incipiente en comparación con el otro caso bajo estudio, la discusión sobre cómo definir qué sería un 'humedal' esconde un profundo debate sobre cuáles son los límites del discurso técnico-científico al entrar en colisión con los intereses de otros agentes sociales, sean los de los grupos económicos concentrados o la de cualquier otro actor que pretenda llevar adelante actividades que impliquen ciertos grados de alteración de aquello que llamamos naturaleza. Si en cualquier norma que prescriba las formas de uso y apropiación de los humedales es evidente la dimensión política, la existencia de definiciones distintas que implicarían el ordenamiento del $11 \%$ (en un caso) o del $25 \%$ (en otro) de la superficie nacional resalta el carácter político de un elemento que, a priori, caracterizaríamos como (únicamente) técnico.

A modo de cierre, coincidimos con Swyngedouw (2011) en que la condición post-política tiene como fin "vaciar la arena política de todo desacuerdo o crítica radical", y busca resolver toda situación problemática "mediante acuerdos técnicos a través de la producción de consensos" (57-59). La investigación de Ferguson (1997) en Lesoto muestra de qué formas las instituciones de desarrollo rural operan como una máquina anti-política que despolitiza su accionar, pese a que simultáneamente lleva adelante su propia operación política de expansión continua en el tiempo. La cuestión del desarrollo, así, es uno de los dominios en los que se expresa esta condición. La cuestión ambiental, sostenemos, también lo es.

Sin embargo, siguiendo a Foucault (1979), “el conjunto de las relaciones de fuerza existentes en una sociedad dada constituye el dominio de la política, y una política es una estrategia más o menos global que intenta coordinar y darles un sentido a estas relaciones de fuerza" (p. 158). Y "decir que todo es político quiere decir esta omnipresencia de las relaciones de fuerza y su inmanencia en un campo político" (p. 159, cursivas en el original). Si sostenemos que los consensos no son afirmaciones absolutas compartidas por todos los agentes sino disensos temporalmente estabilizados y también comprendemos el carácter político de toda propuesta de intervención en material ambiental, los acuerdos técnicos resultan ser una condición necesaria pero no suficiente para la producción de consensos que tengan mayores grados de estabilidad a lo largo del tiempo y permitan coordinar y darles un sentido a las relaciones de fuerza en determinada dirección.

En síntesis, dado que el ordenamiento ambiental del territorio inevitablemente produce conflictos entre agentes sociales con diferentes intereses y posiciones sobre cómo deberían ser las cosas (esto es, conflictos políticos), afirmamos que éstos han de ser trabajados en términos políticos. Como señalan Beltrán y Vaccaro (2011), toda normativa ambiental supone una intervención que busca modificar las situaciones y las relaciones preexistentes y orientarlas en una nueva dirección (o bien reafirmar las existentes), y por lo tanto todo proceso de conservación es esencialmente político. Si la despolitización de todo lo vinculado al dominio de "lo natural" es uno de los mecanismos que han llevado al establecimiento de las situaciones y relaciones que hoy se buscan modificar, su repolitización sienta las bases para que los diversos agentes sociales puedan operar (políticamente) en estos ámbitos. Sólo de este modo, creemos, podrá avanzarse en la producción de nuevos ordenamientos del territorio que favorezcan formas alternativas de apropiación de la naturaleza que beneficien a los sectores históricamente más perjudicados por el avance del capital.

Agradecimientos. Agradecemos al CONICET por la beca doctoral recibida por ambos autores para los períodos 2017-2022 y 20182023, respectivamente, y a la Universidad de Buenos Aires por la beca de maestría que financió los estudios del primer autor en el período 2014-2017. Agradecemos también a la Universidad por el financiamiento de los proyectos de investigación en que nuestros trabajos se insertan (20020130100147BA, 20020170100492BA y 20020170100346BA), a través de los cuales continuamos realizado nuestro trabajo de campo en la actualidad. Finalmente, agradecemos a los dos revisores anónimos, cuyos aportes nos permitieron mejorar sustantivamente la calidad y claridad del artículo. 


\section{REFERENCIAS}

Aguiar, S., M. Mastrangelo, M. A. García Collazo, G. Camba Sans, C. Mosso, L. Ciuffoli, M. Schmidt, M. Vallejos, L. Langbehn, D. Cáceres, G. Merlinsky, J. Paruelo, L. Seghezzo, L. Staiano, M. Texeira, J. Volante, and S. Verón. 2018. ¿Cuál es la situación de la Ley de Bosques en la Región Chaqueña a diez años de su sanción? Revisar su pasado para discutir su futuro. Ecología Austral 28:400-417. https:/ / doi.org/10.25260/EA.18.28.2.0.677.

Balsa, J. 2011. Aspectos discursivos de la construcción de la hegemonía. Identidades 1(1):70-90.

Beltrán, O., J. Pascual Fernández, and I. Vaccaro. 2008. Introducción. Espacios naturales protegidos, política y cultura. Pp. 11-25 en O. Beltrán, J. Pascual Fernández and I. Vaccaro (eds.). Patrimonialización de la naturaleza. El marco social de las políticas ambientales. Ankulegi Antropologia Elkartea, Donostia, España.

Beltrán, O., and I. Vaccaro. 2011. Especies invasoras v especies protegidas. Fauna, política y cultura en el Pirineo Central. En IX Reuniao de Antropologia do Mercosul. Curitiba, Brasil.

Blois, M. L. 2017. Ciencia, glifosato y formas de vida. Una mirada antropológica sobre el debate en torno a los agroquímicos, Universidad de Buenos Aires, Facultad de Filosofía y Letras.

Bottaro, L., and M. Sola Álvarez. 2018. Los vaivenes de la legislación protectora de glaciares en Argentina. Los conflictos por la megaminería más allá de la escala local. Pp. 181-202 en L. Bottaro and M. Sola Álvarez (eds.). Agua y megaproyectos mineros en América Latina. Ediciones UNGS, Buenos Aires, Argentina.

Brosius, J. P. 1999. Analyses and interventions: anthropological engagements with environmentalism. Current Anthropology 40:277-310. https://doi.org/10.1086/200019.

Castro, H. 2011. Naturaleza y ambiente. Significados en contexto. Pp. 43-74 en R. Gurevich (comp.). Ambiente y educación. Una apuesta al futuro. Editorial Paidós, Buenos Aires, Argentina.

De la Vega, C. 2017. Institucionalidad ambiental y procesos de conflictividad social: una mirada política en los casos de las provincias de Córdoba y La Rioja en Argentina. Estado and Comunes. Revista de Política y Problemas Públicos 2(5):63-92. https://doi.org/10.37228/estado_comunes.v2.n5.2017.53.

Esain, J. A. 2004. El federalismo ambiental. Reparto de competencias legislativas en materia ambiental en la Constitución Nacional y la Ley General del Ambiente 25.675. Jurisprudencia Argentina 2004-I-776.

Ferguson, J. 1997 [1959]. The anti-politics machine: "development", depoliticization and bureaucratic power in Lesotho. University of Minneapolis Press, Minneapolis, USA.

Ferrero, B., and C. De Micco. 2011. Nuevas conformaciones de territorialidad en Misiones: problemas sociales y ambientalismo. Pp. 175-199 en A. Mastrángelo and V. Trpin (eds.). Entre chacras y plantaciones: trabajo rural y territorio en producciones que Argentina exporta. Fundación CICCUS, Buenos Aires, Argentina.

Foucault, M. 1979. Microfísica del poder. Ediciones de La Piqueta, Madrid, España.

García Collazo, M. A., A. Panizza, and J. Paruelo. 2013. Ordenamiento Territorial de Bosques Nativos: Resultados de la zonificación realizada por provincias del Norte argentino. Ecología Austral 23:97-107.

Guber, R. 2001. La etnografía. Método, campo y reflexividad. Editorial Norma, Buenos Aires, Argentina.

Gurvich, D., D. Renison, and F. Barri. 2009. El rol del ecólogo ante la crisis ambiental actual. Ecología Austral 19: 233-238.

Gutiérrez, R. 2017. La confrontación de coaliciones sociedad-estado: la política de protección de bosques nativos en Argentina (2004-2015). Revista SAAP (Sociedad Argentina de Analísis Político) 11(2):283-312.

IANIGLA. 2010. Inventario Nacional de Glaciares y Ambiente Periglacial: Fundamentos y Cronograma de Ejecución. Editado por CONICET y Ministerio de Ambiente y Desarrollo Sustentable de la Nación.

Isla Raffaele, M. L. 2015. El papel de la Ley de Glaciares en las disputas por la megaminería a cielo abierto en Argentina. Tesis de Licenciatura. Facultad de Agronomía, Universidad de Buenos Aires, Buenos Aires. Argentina. Pp. 80.

Isla Raffaele, M. L. 2016. El proceso de juridificación de la Ley de Glaciares en las disputas por la Megaminería en Argentina. Ecología Política 51:103-107.

Isla Raffaele, M. L. 2017. Ley de Glaciares: debates y controversias por la megaminería. En III Jornadas Nacionales de Ecología Política. San Juan, Argentina.

Isla Raffaele, M. L. 2019. Procesos de [des/re]territorialización en Iglesia y Jáchal a partir de la instalación del emprendimiento Veladero (San Juan, Argentina, 2004-2019). Revista del CESLA, International Latin American Studies Review 23:89-110.

Iud, D. 2011. La protección de los glaciares. Realidad Económica 257:112-137.

Langbehn, L. 2016. Arenas públicas, modelos de desarrollo y políticas de protección del ambiente: la Ley de Bosques entre "conservación" y "producción". Pp. 141-168 en G Merlinsky (ed.). Cartografías del conflicto ambiental 2. Fundación CICCUS, Buenos Aires, Argentina. https://doi.org/10.2307/j.ctvt6rkxj.9.

Jaime, F. M., G. Dufour, M. Alessandro, and P. Amaya. 2013. Introducción al análisis de las políticas públicas. Florencio Varela: Universidad Nacional Arturo Jauretche.

Maffei, M. 2010. Ley de Glaciares en Argentina. Proceso y Perspectiva Regional. Seminario Taller Glaciares, Agua y Cambio Climático - Justicia Climática y Desafíos para los países andinos del Cono Sur, Buenos Aires, Argentina.

Martínez Alier, J. 2012. El ecologismo de los pobres, veinte años después: India, México y Perú. Nostromo. Revista Crítica Latinoamericana 4(5):57-76.

MAyDS. 2016. Ley $N^{\circ} 26331$ de presupuestos mínimos de protección ambiental de los bosques nativos: informe de estado de implementación 2010-2015. Editado por Ministerio de Ambiente y Desarrollo Sustentable de la Nación. 
Ministerio de Ambiente y Desarrollo Sustentable de la Nación, and CONICET. 2018. Resumen ejecutivo de los resultados del Inventario Nacional de Glaciares. URL: https: / tinyurl.com/ssegmd5.

Muzzopappa, E., and C. Villalta. 2011. Los documentos como campo. Reflexiones teórico-metodológicas sobre un enfoque etnográfico de archivos y documentos estatales. Revista Colombiana de Antropología 47(1):13-42.

Monkes, J. 2017. Los humedales en disputa: discursos y estrategias en torno a la formulación de una ley nacional de conservación de humedales. Tesis de Licenciatura. Facultad de Agronomía, Universidad de Buenos Aires, Buenos Aires. Argentina. Pp. 139.

Morton, T. 2007. Ecology without nature. Harvard University Press, Cambridge, Massachussets, USA.

Packmann, M. 2014. Del veto a la sanción: un análisis político-institucional de la Ley de glaciares. En VIII Jornadas de sociología de la Universidad Nacional de la Plata. Buenos Aires, Argentina.

Paruelo, J. 2009. En relación con el artículo ‘El rol del ecólogo ante la actual crisis ambiental', de Gurvich et al., en este número. Ecología Austral 19:255-258.

Penalva Verdú, C., A. Alaminos Chica, F. J. Francés García, and Ó. A. Santacreu Fernández. 2015. La investigación cualitativa: técnicas de investigación y análisis con Atlas.Ti. PYDLOS Ediciones, Cuenca, Ecuador.

Rojas, F., and L. Wagner. En prensa. Inventario de glaciares en Argentina: polémicas públicas y disputas de sentido. En M. Miraglia y A. M. Franca (comp.). Paisaje y patrimonio: impresiones de la historia en el ambiente natural. Universidad Nacional de Quilmes-TESEO, Buenos Aires, Argentina.

Ryan, D. 2014. Política y ambiente en la Argentina: ¿un caso de baja politización? Análisis de la aprobación de las leyes de bosques nativos y protección de glaciares. Revista Estado y Políticas Públicas 3:22-32.

Sede, S. 2011. La Ley de Protección de los Glaciares. PETROPRESS 22:18-22.

Shore, C. 2010. La antropología y el estudio de la política pública. Reflexiones sobre la 'formulación' de las políticas. Antípoda. Revista de Antropología y Arqueología 10:21-49. https://doi.org/10.7440/antipoda10.2010.03.

Straccia, P. 2019. "Esto lo tenemos que solucionar desde adentro". El uso político de la identidad 'isleña' en un área del Delta del Río Paraná en los procesos de institucionalización de leyes ambientales. Tesis de Maestría. Facultad de Filosofía y Letras, Universidad de Buenos Aires, Buenos Aires, Argentina.

Straccia, P., and C. Pizarro. 2017. Controversias acerca del concepto servicios ecosistémicos. Resignificaciones sobre el impacto de la forestación en los humedales del Delta Inferior del Río Paraná. Agronomía y Ambiente. Revista de la Facultad de Agronomía 37(2):99-113.

Straccia, P., and C. Pizarro. 2019. Ecología política: aportes de la sociología y de la antropología. Cuadernos de Desarrollo Rural 16(84). https://doi.org/10.11144/Javeriana.cdr16-84.epas.

Swyngedouw, E. 2011. ¡La naturaleza no existe!. La sostenibilidad como síntoma de una planificación despolitizada. Urban 1:41-66.

Vera Alpuche, J. 2012. La dimensión discursiva en los conflictos socioambientales: apuntes para un método de análisis de discurso desde la ecología política. Revista Interdisciplinaria de Estudios Sociales 5:135-160. 